\begin{tabular}{c} 
Volume and Issues Obtainable at Center for Sustainability Research and Consultancy \\
Journal of Accounting and Finance in Emerging Economies \\
ISSN: 2519-0318ISSN (E) 2518-8488 \\
Volume 2: Issue 2 December 2016 \\
CSRᄃ \\
Journal homepage: www.publishing.globalcsrc.org/jafee \\
\hline
\end{tabular}

\title{
The Analysis of the Validity of Capital Asset Pricing Model: Evidence from Pakistan Stock Exchange
}

\author{
${ }^{1}$ Adeel Akhtar, ${ }^{2}$ Muhammad Shaukat Malik, ${ }^{3}$ Imran Nusrat, ${ }^{4}$ Allah Bakhsh \\ ${ }^{1}$ Assistant Professor, BahauddinZakariyaUniversity Multan, Pakistan, adeel.akhtar@bzu.edu.pk \\ ${ }^{2}$ Professor, BahauddinZakariyaUniversity Multan, Pakistan, shoukatmalik@bzu.edu.pk \\ ${ }^{3}$ Bahauddin ZakariyaUniversity Multan, Pakistan Imrannusrat341 @ yahoo.com \\ ${ }^{4}$ Assistant Professor, BahauddinZakariyaUniversity Multan, Pakistan, abkhan@bzu.edu.pk
}

\begin{tabular}{l}
\hline ARTICLEDETAILS \\
\hline History \\
Revised format: Nov 2016 \\
AvailableOnline: Dec 2016
\end{tabular}

\section{Keywords \\ $C A P M$,}

financial Crisis, individual Stock Returns, PSE 100 Index

JEL Classification:

G31, G01, G10

\begin{abstract}
The aim of this study was to find evidence for the implementation of capital asset pricing model (CAPM) on companies listed at Pakistan Stock Exchange before, during and after financial crisis. The data of 50 companies were collected ranging from various sectors of Pakistan stock exchange. Data were divided into 3 different groups: year 2005-2007, 2008-2010 and 2011-2013. Regression analysis was conducted for testing the hypotheses by taking Pakistan stock exchange 100 index as independent variable and individual stocks return as dependent variable.Three different levels of significance have been used: significance at $1 \%$, significance at $5 \%$, and significance at $10 \%$. The results suggested that in Pakistan different business organizations due to narrow scope of business are relatively less diversified and have relatively high flexibility of responding unexpected and uncertain events, influencing overall market performance. Similarly, large number of companies, specifically during period of financial crisis, are affected and influenced by numerous risk factors. It was concluded that fair prices of stock cannot be determined with the help of CAPM in Pakistan.
\end{abstract}

(C) 2016 The authors, under a Creative Commons AttributionNonCommercial 4.0

Corresponding author's email address: adeel.akhtar@bzu.edu.pk

Recommended citation:Akhtar, A., Malik, M. S., Nusrat, I. and Bakhsh, A. (2016).The Analysis of the Validity of Capital Asset Pricing Model: Evidence from Pakistan Stock Exchange. Journal of Accounting and Finance in Emerging Economies, 2(2) 57-68

\section{Introduction}

The theory on asset pricing can be traced back to the seventeenth century when Bernoulli (1738) proposed that the value of an asset can be determined by assessing the utility that it yields rather than determining its value based on its price. Modern financial theory is based on three central assumptions: markets are efficient, arbitrage opportunity exists and investors are rational.

CAPM propose that the expected return on an investment in the risky asset is influenced by two types of 
risks: systematic risk (non-diversifiable risk) and unsystematic risk (diversifiable risk).

Asset pricing models provide a meaningful measure of the expected return of an asset which the investor gets by taking on a certain level of risk. Once the expected return is calculated by using an asset pricing model, the future cash flows of the asset can be discounted to their present value employing the same rate of expected return in order to estimate whether the asset is overvalued or undervalued.

An exhaustive literature exists in support and against the validity of CAPM and the empirical evidence has shown that the relevance of CAPM differs in developed and emerging markets. This papers aims to test the validity of the capital asset pricing model for companies listed at the Pakistan stock exchange (PSE) before, during, and after financial crisis. This research study is the comparative research study in which validity of CAPM is tested during three different periods including period i.e. from year 2005 to year 2007, from year 2008 to 2010 and from year 2011 to 2013. The main questions asked in this paper are as follows.

i. What is the validity of the estimating future returns based on CAPM before the financial crisis?

ii. What is the validity of the estimating future returns based on CAPM during the financial crisis?

iii. What is the validity of the estimating future returns based on CAPM after the financial crisis?

This paper is of practical significance the financial advisors and individual investorsmaking some predictions about the future and, therefore, affect their financial advice and investment decision making. The result of this paper can also help in determining the risk-return relationship as an essential part for many financial applications and key components.

\section{Literature Review}

The CAPM conveys the notion that securities are priced so that the expected returns will compensate investors for the expected risks. There are two fundamental relationships: capital market line and security market line

The model is an extension of Markowitz's (1952) portfolio theory. Sharp (1965), Linter (1965) and Black et al (1972) are the researchers who developed the CAPM based on the assumptions and notions of portfolio theory.

- Market has many investors

- They are investing in the same time period

- Sale has no tax on it

- Market has no labor cost

- All lend and investors borrow unlimited risk free Prices

- Investors are rational

- Investors of all as equal and about the same expectations of investors expected revenue

\subsection{Arguments against (CAPM)}

Laubscher, (2002) the CAPM is incorrect and has some errors and arbitrage pricing theory which was developed in 1976 by Ross represents a good explanation of the return CAPM. BurcKayahan,(2007) and Ahmad, (2008) also accomplished that CAPM is not useful.Cheung Wong et al (1992) analysis from 1980 to 1989 study period, the Hong Kong stock market the relationship between risk and return, the CAP model application and concluded that there is very poor health in Hong Kong Stock Exchange. Wong et al (1993) analyzed the Korean stock exchanges and Taiwan. It concluded that the application of the cap health model is very weak in both Markets, especially in the Taiwan stock exchange. Gomez and 
Zapatro (2003) analyzed data of 220 US stocks in 1973 and 1978 covering the period of twenty six year old. The systematic patterns of two betas and active market, taking into account risk factors, the management of risk factors. Their conclusion was the result of both their betas is preferable than the CAPM model.Hanif (2010) examining the tobacco sector of Pakistan stock exchange to check the validity of CAPM model the study conducted by taking the data from Pakistan stock exchange for the period 2004 to 2007 he found that CAPM is not applicable.

\subsection{Arguments for (CAPM)}

Jensen and Sholes (1972), New York, analyzed the impact of the CAPM by taking 41 years data and covered the period from 1926 to 1966, they concluded that there is a positive relationship between beta and average yields. Lau \& Quay (1974) analyzed the validity of the model in Tokyo Stock Exchange. The researcher used the data of five years 1964 to 1969, 100 companies. He concluded that the CAPM provide actual return at Tokyo stock exchange. Jagannath\& Wang (1993) argues that the capital asset pricing model (CAPM) used widely for Expected investment \& return of shares among investors for risk, portfolio administrations. Fraser \&Hamelink (2004) make comparison between the results of the CAP and GARCH models. They were questioned on the London Stock Exchange market takes seven sectors of the twenty Two years Period (1975-1996). They found that in more detail results of the model GARCH, CAP expected to announce the return of comparables model. Raei and Mohammadi (2008) A NASDAQ stock market valued the company to analyze the data, since 1994. They came to the conclusion that period twelve year him method for calculating the return expected in 2005 change; CAPM is only useful or calculating the cost of equity.

\section{Methodology and Sampling}

Aim of this study is to test the validity of CAPM before financial crisis of 2008, during period of financial crisis and after the financial crisis and for this 50 different companies were selected from PSE (Pakistan Stock Exchange). This research therefore provides the comparative analysis of three different periods. The reasons for selecting this time period is the availability of data during this period of time and during August, 2008, the PSE index was starting moving downward at its extreme and stock market was unable to normalize for 8 to 9 months.

\subsection{Population andSample}

During first stage, 10 different sectors from 35 sectors of PSE were selected at random. The sample taken during course of this study for analysis and achievement of set goals and objectives was comprised of 50 different companies, 5 from every sector. The sampling method used to select the companies for data collection was multi-phase random sampling.

\subsection{Data Sources}

Different secondary data sources are used to collect the data and for this study secondary data is collected through internet and websites specifically from the website of PSE and Business Recorder. Types of data collected for analysis include daily stock prices for three different periods, market index for these periods, and 3 months T-Bills rate for mentioned period.

\section{Calculation of Stock Return}

Daily stock return for each of 50 stocks for three different periods was calculated based on daily closing prices. For example to calculate the market return at time t, closing prices of stock at time t- 1 was deducted from closing prices of that stock at time $t$ and then divided by closing price at time $t-1$. In other words formula used in this regards was as follows.

Return of Stock 1 at Time $\mathrm{t}=($ Closing Price of Stock 1 at time $\mathrm{t}-$ Closing Price of Stock 1 at time $\mathrm{t}-1) /$ 
Closing Price of Stock 1 at time t-1

\section{Calculation of Market Return}

As mentioned earlier, in order to calculate the market return or return on market portfolio, PSE 100 index was used. For this purpose daily values of PSE 100 index were used for three periods and calculate the market return. Market return was calculated through daily closing of PSE 100 Index for example to calculate the market return at time t, PSE 100 index at time t-1 was deducted from closing value of PSE 100 at time $t$ and then divided by closing value of PSE 100 index at time $t-1$ to convert it in percentage. The formula used for calculating market return at time $t$, is summarized as under.

Market Return at Time $\mathrm{t}=($ Closing Value of PSE-100 Index at Time $\mathrm{t}-$ Closing Value of PSE-100 Index at Time $\mathrm{t}-1$ ) / Closing Value of PSE-100 Index at Time $\mathrm{t}-1$

\subsection{Regression Model}

After calculating the daily stock returns and market returns, regression was used to calculate the market beta. In other words, both daily stock return and daily market return were regressed by using MS Excel. Regression analysis resulted into calculation of Beta for individual stock. The beta for individual stock was used to apply the CAPM. Table 1 is summarizing beta for each stock.

\section{Risk Free Rate of Return}

The risk free asset in order to calculate the expected or required rate of return through application of CAPM is an asset which yields certain returns. Practically and in reality, there is no any asset exists in Pakistan market that has certain return and risk free asset proxy investors use the government issued securities. Therefore return on these, government issued securities can be used as proxy for risk free rate of return. Even government issued securities in Pakistan are also facing the inflation risk. For this purpose, in this study, 3 months T-Bills rate issues by government was taken as proxy to risk free rate. 3 months T-Bills rate available on secondary data sources was monthly rate therefore was annualized by using formula of effective rate of return and it was assumed that for particular month, rate remains same.

\section{Model Specification (CAPM-Single Factor Model)}

The CAPM (Capital Asset Pricing Model) provides the non-diversifiable risk asset and systematic or market risk is represented through beta. In case if the investor formulate well-diversified portfolio of securities or assets, the Capital Asset Pricing Model can be used for quantification of relationship between assets beta and corresponding expected returns. In case if the investor is exposed to the systematic or non-diversifiable risk while making investments in portfolio, then the portfolio beta is the defining factors of expected or required return. The CAPM has underlying assumption that the market beta is the only risk factor, has been priced in stock returns. The single factor CAPM used during course of this study in order to determine the expected or required rate of return on investment is summarized as under.

$$
R_{i t}=R_{f}+\left(R_{\mathrm{m} t}-R_{f}\right) \beta_{1 t}
$$

With $\mathrm{t}=1,2,3 \ldots, \mathrm{T}$

In this equation, the $\mathrm{R}_{\mathrm{it}}$ is representing the required or expected return on stock $i$ in time $t$. $\mathrm{R}_{\mathrm{f}}$ is representing the risk free rate of return which in this case is the rate of return on 3-Months T-Bills, $R_{m t}-$ 
$R_{f}$ is representing the market risk premium. Finally the coefficient $\beta_{1 t}$ is representing the risk sensitivity of returns for market risk and is determined through regression and summarized in table 1 .

Similarly, for testing the CAPM, multivariate regression framework was used through transformation of equation above. The transformation of equation above is made into simplest model of time series which is summarized as under.

$$
\begin{aligned}
& R_{i t}-R_{f}=\alpha_{i}+\left(R_{m t}-R_{f}\right) \beta_{1 t}+\epsilon_{t} \\
& E R_{i t}=\alpha_{i}+\left(R_{m t}-R_{f}\right) \beta_{1 t}+\epsilon_{t} \ldots \ldots
\end{aligned}
$$

In equation above, the $\mathrm{ER}_{\mathrm{it}}=\mathrm{R}_{\mathrm{it}}-\mathrm{R}_{\mathrm{f}}$ is representing stock return at point in time $\mathrm{t}$. $\alpha_{\mathrm{i}}$ is representing the value of regression equation's intercept and summarizes the non-market component of return. $\epsilon_{t}$ is representing error term. The error term in this case refers to the random return component which is due to the unexpected events related to the particular security $i$. For the sake of simplification, the assumption was made that $\epsilon_{\mathrm{t}}$ has multivariate normal distribution and therefore it is identically and independently distributed over period of time. The model summarized above is the single factor model, used for individual security. This model can also be used for the stock portfolios and for this purpose, by replacing $i$ with $\mathrm{p}$ for representing the portfolio of stocks, the single factor model for portfolio would be as follows.

$$
E R_{p t}=\alpha_{p}+\left(R_{m t}-R_{f}\right) \beta_{1 t}+\epsilon_{t}
$$

In equation above the $\mathrm{ER}_{\mathrm{pt}}$ is representing portfolio's excess return time $t$, and $\alpha_{\mathrm{p}}$ is representing the average of all individual alphas of the stocks included in the portfolio.

\subsection{Hypotheses}

H1: Individual stocks registered at PSE were fairly priced before the period of financial crisis: 2005-07. H2: Individual stocks registered at PSE were fairly priced during the period of financial crisis: 2008-10. H3: Individual stocks registered at PSE were fairly priced after the period of financial crisis: 2011-13.

\section{Results and Discussions}

Table 1 is representing the CAPM regress on 50 selected securities from 10 different randomly selected sectors of PSE. The CAPM assumes that beta of market portfolio is the single and only risk factor, explains the cross-sectional variation of expected stock returns. The results of analysis however suggested and revealed that there is weak relation between average return on securities and the market beta. Additionally, the coefficient of all securities is insignificant with exception of only 5 securities including NBP, PCAL, ENGRO, PGCL and DAWH were significant at $10 \%$ level of significance. The regression interception $(\alpha)$ of 40 out of 50 securities was significant. This shows that for these securities, the CAPM significantly understates the returns on securities. The securities for which CAPM is understating returns are major players in their respective sectors.

For the CAPM Model to hold, the intercepts of regress should be zero. But the analysis suggested that for 50 out of 50 securities have non-zero regression intercept therefore there might some other factors that affect the returns of securities. This is contrary to the preposition of Sharpe (1964) that the only factor explaining the cross-sectional variation in expected return of an asset is the market risk. It has also been observed during course of analysis that the value of $\mathrm{R}^{2}$ calculated for all the 50 securities is very low. Specifically, during the period of financial crisis the value of $\mathrm{R}^{2}$ is very low showing that there are 
other factors that determine the return on securities other than that of market risk.

The overall findings of research and analysis suggested that the market risk in PSE market is not the only factor that can explain the cross-sectional variation of expected returns and during period of financial crisis, the CAPM does not hold i.e. unable to determine the fair prices of securities. In other words, during normal circumstances i.e. during period 1 and period 3, CAPM determined the fair prices of securities or securities were fairly prices but during period of financial crisis i.e. during 2008, 2009 and 2010, the CAPM was unable to determine fair prices of securities in market or securities were not prices fairly and were either overprices or underpriced significantly.

It is observed that the market return during period 1(2005-07) shown positive trend and intra-day market return calculated based on PSE-100 index shown irregular trend i.e. positive and negative but during period 1 as a whole, positive trend is observed in intra-day market return. During period 2(200810), the PSE-100 index declined and shown high variation therefore the intra-day market return declined during period of financial crisis. During period 3(2011-13), The indexes increased due to improved market activities, trading and demand for different stocks, increased investment in stock market and moved the stock slightly up. It has observed that during period 3, the intra-day market return improved and shown positive trend. The results summarized in table 1 are tested at $10 \%, 5 \%$ and $1 \%$ level of significance and results shown that during period 1 i.e. during 2005 to 2007, 21 out 50 securities were significant at $1 \%$ level of significance while 12 out of 50 securities were significant at $5 \%$ level of significance while remaining 17 securities out of 50 were significant at 10 percent level of significance. During period 2 i.e. 2008 to 2010, 26 out 50 securities were significant at $1 \%$ level of significance while 15 out of 50 securities were significant at $5 \%$ level of significance while remaining 9 securities out of 50 were significant at 10 percent level of significance. During period 3 i.e. 2011 to 2013, 19 out 50 securities were significant at $1 \%$ level of significance while 10 out of 50 securities were significant at $5 \%$ level of significance while remaining 21 securities out of 50 were significant at 10 percent level of significance.

\section{Conclusions}

The Capital asset pricing model is easy to use model and is helpful in providing the first-hand information about the security's risk to investors. The results of the study showed a weak relationship of CAPM between the beta and the average market return of individual stock. The coefficient of all securities selected for period 1 and period 3 were insignificant except 3 securities including ENGRO, ATHL and PGCL which were significant at 10 percent level of significance.The critical analysis of prices fluctuations for every selected security (50 stocks from PSE were selected at random), it is observed that stock prices during 2008 to 2010 were decreased. The analysis of calculated return on individual stocks suggested that investors, on average, experienced negative returns during that period. From 2005 to 2007 prices of individual stocks have shown irregular trends, therefore, investors had experienced irregular stock returns. The price behavior of different stocks from 2011 to 2013 was fluctuating as well. Therefore, it is clear from the above discussion that the CAPM was not able to predict the fair stock prices before the period of financial crises (2005-07), during the period of financial crises (2008-10) and after the period of financial crises (2011-13), therefore, our findings are consistent with the findings of Wong (1993), Hordal\&bjorn (1998), Gomez and Zapatro (2003), Laubscher (2002), Bhatii\&Hanif (2010), Javid and Eatzaz (2008) and Hanif (2010).

\section{Recommendation and Future Research Area}

CAPM takes the beta of stock as sole factor to explain the risk variation in the market, which is the major reason for it non-applicability in the determination of stock prices. It is, therefore, recommended that investors should use some other models (GARCH, APT) to predict the stock prices in Pakistan. Further studies may be conducted by taking different time periods and larger samples as well as some 
other financial models may be applied to predict the market prices of stocks in Pakistan and in other countries.

\section{References}

Bernouilli, D. (1954). Exposition of a new theory on the measurement of risk Econometrika 22, 2336. Publicación original, 1738.

Bjorn \&Hordahl, (1998). Testing the Conditional CAPM using Multivariate GARCH-M.Journal of Applied Financial Economics, vol. 8.

Cheung YL, Wong KT (1992). An assessment of Risk and Return: some empirical findings from Hong Kong Stock Exchange. Appl. Fina. Econ., 2: 105-114.

Cheung,Y. L. Wong, K. A. \& Ho, Y. K. (1993). The pricing of risky assets in two emerging asian markets: Korea and Taiwan. Applied FInancial Economics, Vol. 3 , 315-324.

Fraser \&Hamelink, (2004). Time-Varying Betas and the Cross-Sectional Return Risk Relation: Evidence from the UK. The European Journal of Finance, Vol. 10.

Gomez \&Zapatro, (2003). Asset Pricing Implications of Benchmarking: A TwoFactor CAPM. The European Journal of Finance, Vol. 9.

Hanif M (2010). Testing Application of CAP Model on PSE- Pakistan: A Case Study on Tobacco Sector.Manag.Account., 2(1):192-215.

Hanif, M. \&Bhatti, U. (Issue, 20, 2010). Validity of Capital Assets Pricing Model: Evidence from PSE-Pakistan. European Journal of Economics, Finance and Administrative Sciences

Jagganath, R. \& Wang, Z. (1993). CAPM is alive as well. The Fourh Annual Conference on Financial Economics and Accounting Vol 1, No 5, 2-57.

Javid, A. Y., \& Ahmed, E. (2008). Test of multi-moment capital asset pricing model: Evidence from Pakistan Stock Exchange (No. 2008: 49). Pakistan Institute of Development Economics.

Jensen, M. C., Black, F., \& Scholes, M. S. (1972). The capital asset pricing model: Some empirical tests.

Kayahan, B., \&Stengos, T. (2007).Testing the capital asset pricing model with local maximum likelihood methods. Mathematical and Computer Modelling, 46(1), 138-150.

Lintner, J. (1965). The valuation of risk assets and the selection of risky investments in stock portfolios and capital budgets. The review of economics and statistics, 13-37.

Lau, S. C., Quay, S. R., \& Ramsey, C. M. (1974).The Tokyo stock exchange and the capital asset pricing model. The Journal of Finance, 29(2), 507-514.

Markowitz, H. (1952). Portfolio selection. The journal of finance, 7(1), 77-91.

Raei, R., \&Mohammadi, S. (2008). Fractional return and fractional CAPM.

Laubscher, E. R. (2002). A review of the theory of and evidence on the use of the capital asset pricing model to estimate expected share returns.Meditari Accountancy Research, 10(1), 131-146.

Sharpe, W. F. (1964). Capital Asset Prices: A theory of Market Equilibrium under conditions of Risk. Journal of Finance XIX, 425-442 


\section{Appendix Table 1}

\begin{tabular}{|c|c|c|c|c|c|c|c|c|}
\hline Sr. & Symbol & Period & $\begin{array}{l}\text { R- } \\
\text { Square } \\
\end{array}$ & $\begin{array}{l}\text { Adj. R } \\
\text { Square }\end{array}$ & Beta & $\begin{array}{l}\text { P- } \\
\text { Value }\end{array}$ & $t(\alpha)$ & $t(\beta)$ \\
\hline \multicolumn{9}{|c|}{ Automobiles } \\
\hline \multirow{3}{*}{1} & \multirow{3}{*}{ ATLH } & 1 & 0.0021 & -0.0004 & 0.0256 & 0.8111 & 0.2391 & 0.9202 \\
\hline & & 2 & 0.0000 & -0.0025 & 0.0277 & 0.1038 & 1.6307 & 0.0900 \\
\hline & & 3 & 0.0052 & 0.0027 & 0.0232 & 0.2913 & 1.0568 & -1.4374 \\
\hline \multirow{3}{*}{2} & \multirow{3}{*}{ DFML } & 1 & 0.0026 & 0.0012 & 0.0939 & 0.4160 & 0.8138 & -1.3713 \\
\hline & & 2 & 0.0524 & 0.0510 & 0.0608 & 0.8962 & -0.1305 & 6.1793 \\
\hline & & 3 & 0.0199 & 0.0184 & 0.0586 & 0.3290 & 0.9768 & -3.7412 \\
\hline \multirow{3}{*}{3} & \multirow{3}{*}{ GAIL } & 1 & 0.0000 & -0.0021 & 0.0833 & 0.7190 & 0.3600 & -0.1417 \\
\hline & & 2 & 0.0003 & -0.0019 & 0.0626 & 0.9734 & -0.0334 & -0.3461 \\
\hline & & 3 & 0.0034 & 0.0013 & 0.0732 & 0.2272 & 1.2092 & 1.2643 \\
\hline \multirow{3}{*}{4} & \multirow{3}{*}{ HCAR } & 1 & 0.0006 & -0.0015 & 0.0950 & 0.6322 & 0.4789 & -0.5261 \\
\hline & & 2 & 0.0087 & 0.0066 & 0.0303 & 0.5446 & 0.6063 & -2.0306 \\
\hline & & 3 & 0.0365 & 0.0344 & 0.0291 & 0.0705 & 1.8125 & -4.2216 \\
\hline \multirow{3}{*}{5} & \multirow{3}{*}{$\begin{array}{l}\text { HINO } \\
\text { PK }\end{array}$} & 1 & 0.0007 & -0.0014 & 0.0809 & 0.1371 & 1.4892 & 0.5678 \\
\hline & & 2 & 0.0003 & -0.0018 & 0.0261 & 0.0427 & -2.0318 & -0.3629 \\
\hline & & 3 & 0.0036 & 0.0015 & 0.0273 & 0.2102 & 1.2546 & -1.3107 \\
\hline \multicolumn{9}{|c|}{ Banks } \\
\hline \multirow{3}{*}{1} & \multirow{3}{*}{ ABL } & 1 & 0.0003 & -0.0018 & 0.0244 & 0.4114 & 0.8221 & -0.3860 \\
\hline & & 2 & 0.0032 & 0.0011 & 0.0249 & 0.0326 & 2.1433 & 1.2259 \\
\hline & & 3 & 0.0009 & -0.0012 & 0.0183 & 0.2078 & 1.2613 & -0.6608 \\
\hline \multirow{3}{*}{2} & \multirow{3}{*}{ BAFL } & 1 & 0.0212 & 0.0192 & 0.0287 & 0.5933 & -0.5344 & 3.1977 \\
\hline & & 2 & 0.0049 & 0.0027 & 0.0276 & 0.8975 & -0.1288 & 1.5171 \\
\hline & & 3 & 0.0438 & 0.0418 & 0.0197 & 0.2468 & 1.1595 & -4.6465 \\
\hline \multirow{3}{*}{3} & \multirow{3}{*}{ BOP } & 1 & 0.0000 & -0.0021 & 0.0285 & 0.9602 & 0.0499 & -0.1332 \\
\hline & & 2 & 0.0206 & 0.0185 & 0.0356 & 0.9312 & 0.0863 & 3.1450 \\
\hline & & 3 & 0.0239 & 0.0218 & 0.0335 & 0.6234 & 0.4913 & -3.3932 \\
\hline \multirow{3}{*}{4} & \multirow{3}{*}{ MEBL } & 1 & 0.0049 & 0.0028 & 0.0257 & 0.3296 & 0.9760 & 1.5262 \\
\hline & & 2 & 0.0002 & -0.0020 & 0.0278 & 0.5527 & 0.5942 & 0.2805 \\
\hline & & 3 & 0.0032 & 0.0011 & 0.0179 & 0.0734 & 1.7941 & -1.2304 \\
\hline \multirow{3}{*}{5} & \multirow{3}{*}{ NBP } & 1 & 0.0009 & -0.0012 & 0.0264 & 0.7946 & 0.2605 & 0.6615 \\
\hline & & 2 & 0.0081 & 0.0059 & 0.0279 & 0.5207 & 0.6427 & 1.9557 \\
\hline & & 3 & 0.0231 & 0.0210 & 0.0243 & 0.8810 & 0.1497 & -3.3387 \\
\hline \multicolumn{9}{|c|}{ Cables } \\
\hline \multirow{3}{*}{1} & \multirow{3}{*}{ JOPP } & 1 & 0.0000 & -0.0021 & 0.0379 & 0.2158 & 1.2394 & -0.0710 \\
\hline & & 2 & 0.0005 & -0.0016 & 0.0462 & 0.1770 & -1.3520 & 0.5076 \\
\hline & & 3 & 0.0100 & 0.0079 & 0.0490 & 0.2252 & 1.2143 & -2.1843 \\
\hline & & 1 & 0.0061 & 0.0040 & 0.0251 & 0.5897 & 0.5396 & 1.6949 \\
\hline 2 & PAEL & 2 & 0.2001 & 0.1984 & 0.0226 & 0.2952 & -1.0480 & 10.8541 \\
\hline & & 3 & 0.0552 & 0.0532 & 0.0437 & 0.2606 & 1.1264 & -5.2441 \\
\hline
\end{tabular}




\begin{tabular}{|c|c|c|c|c|c|c|c|c|}
\hline \multirow{3}{*}{3} & \multirow{3}{*}{ PCAL } & 1 & 0.0043 & 0.0022 & 0.0292 & 0.9964 & -0.0046 & 1.4262 \\
\hline & & 2 & 0.0001 & -0.0020 & 0.0307 & 0.9959 & 0.0051 & -0.2292 \\
\hline & & 3 & 0.0006 & -0.0015 & 0.0283 & 0.2120 & 1.2498 & 0.5513 \\
\hline \multirow{3}{*}{4} & \multirow{3}{*}{ SIE } & 1 & 0.0056 & 0.0035 & 0.0228 & 0.3503 & 0.9349 & -1.6246 \\
\hline & & 2 & 0.0126 & 0.0105 & 0.0239 & 0.6223 & 0.4930 & 2.4483 \\
\hline & & 3 & 0.0356 & 0.0336 & 0.0227 & 0.7172 & 0.3624 & -4.1711 \\
\hline \multirow{3}{*}{5} & \multirow{3}{*}{ SIN } & 1 & 0.0095 & 0.0074 & 0.0340 & 0.9944 & -0.0070 & 2.1263 \\
\hline & & 2 & 0.0155 & 0.0134 & 0.0316 & 0.8257 & -0.2203 & 2.7199 \\
\hline & & 3 & 0.0072 & 0.0051 & 0.0277 & 0.5575 & 0.5869 & -1.8529 \\
\hline \multicolumn{9}{|l|}{ Cements } \\
\hline \multirow{3}{*}{1} & \multirow{3}{*}{ DGKC } & 1 & 0.0029 & 0.0007 & 0.0282 & 0.9211 & -0.0991 & 1.1608 \\
\hline & & 2 & 0.0388 & 0.0368 & 0.0294 & 0.3008 & 1.0359 & 4.3629 \\
\hline & & 3 & 0.0144 & 0.0123 & 0.0204 & 0.0068 & 2.7198 & -2.6259 \\
\hline \multirow{3}{*}{2} & \multirow{3}{*}{ FCCL } & 1 & 0.0087 & 0.0066 & 0.0272 & 0.5005 & -0.6743 & 2.0358 \\
\hline & & 2 & 0.0249 & 0.0228 & 0.0313 & 0.8655 & -0.1695 & 3.4674 \\
\hline & & 3 & 0.0102 & 0.0081 & 0.0292 & 0.0367 & 2.0948 & -2.2007 \\
\hline \multirow{3}{*}{3} & \multirow{3}{*}{ КОНС } & 1 & 0.0000 & -0.0021 & 0.0287 & 0.5565 & -0.5884 & 0.1378 \\
\hline & & 2 & 0.0223 & 0.0202 & 0.0376 & 0.7386 & -0.3339 & 3.2770 \\
\hline & & 3 & 0.0164 & 0.0143 & 0.0278 & 0.0018 & 3.1361 & -2.7997 \\
\hline \multirow{3}{*}{4} & \multirow{3}{*}{ LUCK } & 1 & 0.0017 & -0.0004 & 0.0273 & 0.6112 & 0.5087 & 0.8908 \\
\hline & & 2 & 0.0349 & 0.0328 & 0.0245 & 0.1265 & 1.5308 & 4.1262 \\
\hline & & 3 & 0.0096 & 0.0075 & 0.0162 & 0.0011 & 3.2741 & -2.1364 \\
\hline \multirow{3}{*}{5} & \multirow{3}{*}{ MLCF } & 1 & 0.0010 & -0.0011 & 0.0280 & 0.2620 & -1.1230 & 0.6799 \\
\hline & & 2 & 0.0191 & 0.0170 & 0.0392 & 0.7666 & -0.2970 & 3.0275 \\
\hline & & 3 & 0.0188 & 0.0168 & 0.0400 & 0.0072 & 2.6987 & -3.0074 \\
\hline \multicolumn{9}{|l|}{ Chemicals } \\
\hline \multirow{3}{*}{1} & \multirow{3}{*}{ BERG } & 1 & 0.0005 & -0.0016 & 0.0255 & 0.4414 & 0.7706 & -0.4989 \\
\hline & & 2 & 0.0117 & 0.0101 & 0.0367 & 0.1274 & -1.5265 & 2.6989 \\
\hline & & 3 & 0.0013 & -0.0003 & 0.0273 & 0.0146 & 2.4479 & -0.8911 \\
\hline \multirow{3}{*}{2} & \multirow{3}{*}{ DCH } & 1 & 0.0071 & 0.0055 & 0.0616 & 0.3484 & 0.9385 & 2.1026 \\
\hline & & 2 & 0.0765 & 0.0750 & 0.0518 & 0.7132 & -0.3677 & 7.1422 \\
\hline & & 3 & 0.0001 & -0.0016 & 0.0435 & 0.4170 & 0.8121 & -0.2068 \\
\hline \multirow{3}{*}{3} & & 1 & 0.0003 & -0.0013 & 0.0217 & 0.2017 & 1.2780 & 0.4518 \\
\hline & LINDE & 2 & 0.0020 & 0.0003 & 0.0233 & 0.1290 & -1.5202 & 1.1018 \\
\hline & & 3 & 0.0011 & -0.0005 & 0.0201 & 0.2058 & 1.2665 & -0.8163 \\
\hline & & 1 & 0.0016 & -0.0026 & 0.0548 & 0.4824 & 0.7035 & 0.6141 \\
\hline 4 & PGCL & 2 & 0.0007 & -0.0035 & 0.0380 & 0.5164 & -0.6498 & 0.3988 \\
\hline & & 3 & 0.0022 & 0.0003 & 0.0316 & 0.0009 & 3.3455 & 1.0645 \\
\hline & & 1 & 0.0002 & -0.0018 & 0.0505 & 0.1010 & 1.6431 & 0.3204 \\
\hline 5 & SPL & 2 & 0.0648 & 0.0630 & 0.0284 & 0.3005 & -1.0365 & 5.9099 \\
\hline & & 3 & 0.0000 & -0.0020 & 0.0280 & 0.3103 & 1.0157 & -0.1116 \\
\hline Fertilizers & & & & & & & & \\
\hline 1 & DAWH & 1 & 0.0232 & 0.0131 & 0.0241 & 0.1264 & 1.5419 & 1.5174 \\
\hline
\end{tabular}




\begin{tabular}{|c|c|c|c|c|c|c|c|c|}
\hline & & 2 & 0.2841 & 0.2767 & 0.0128 & 0.6639 & -0.4359 & 6.2040 \\
\hline & & 3 & 0.2588 & 0.2511 & 0.0229 & 0.7381 & -0.3353 & -5.8195 \\
\hline \multirow{3}{*}{2} & \multirow{3}{*}{ ENGRO } & 1 & 0.0034 & -0.0069 & 0.0198 & 0.4670 & 0.7302 & 0.5767 \\
\hline & & 2 & 0.6129 & 0.6089 & 0.0091 & 0.0704 & -1.8293 & 12.3934 \\
\hline & & 3 & 0.2185 & 0.2104 & 0.0231 & 0.6642 & -0.4354 & -5.2078 \\
\hline \multirow{3}{*}{3} & \multirow{3}{*}{ FFBL } & 1 & 0.0861 & 0.0767 & 0.0189 & 0.8312 & -0.2138 & 3.0226 \\
\hline & & 2 & 0.2947 & 0.2874 & 0.0134 & 0.7168 & 0.3639 & 6.3660 \\
\hline & & 3 & 0.0053 & 0.0039 & 0.0174 & 0.6273 & 0.4857 & -1.9571 \\
\hline \multirow{3}{*}{4} & \multirow{3}{*}{ FFC } & 1 & 0.0029 & -0.0074 & 0.0140 & 0.9615 & 0.0483 & 0.5323 \\
\hline & & 2 & 0.2592 & 0.2516 & 0.0098 & 0.6616 & 0.4390 & 5.8262 \\
\hline & & 3 & 0.0651 & 0.0555 & 0.0107 & 0.8664 & 0.1686 & -2.5994 \\
\hline \multirow{3}{*}{5} & \multirow{3}{*}{ SAWEZ } & 1 & 0.0017 & -0.0008 & 0.0305 & 0.0120 & 1.6431 & -0.8189 \\
\hline & & 2 & 0.0008 & -0.0017 & 0.0260 & 0.9552 & -1.0365 & 0.5662 \\
\hline & & 3 & 0.0019 & -0.0006 & 0.0235 & 0.9870 & 1.0157 & -0.8713 \\
\hline \multicolumn{9}{|c|}{ Foods } \\
\hline \multirow{3}{*}{1} & \multirow{3}{*}{ MFFL } & 1 & 0.0020 & 0.0002 & 0.0277 & 0.2673 & 1.1104 & 1.0419 \\
\hline & & 2 & 0.0001 & -0.0025 & 0.0374 & 0.5353 & -0.6205 & -0.1657 \\
\hline & & 3 & 0.0007 & -0.0019 & 0.0332 & 0.0007 & 3.4093 & -0.5151 \\
\hline \multirow{3}{*}{2} & \multirow{3}{*}{ NATF } & 1 & 0.0000 & -0.0019 & 0.0296 & 0.0562 & 1.9142 & 0.1584 \\
\hline & & 2 & 0.0008 & -0.0011 & 0.0295 & 0.8288 & 0.2164 & 0.6486 \\
\hline & & 3 & 0.0056 & 0.0036 & 0.0270 & 0.0018 & 3.1433 & -1.6851 \\
\hline \multirow{3}{*}{3} & \multirow{3}{*}{ NESTLE } & 1 & 0.0024 & 0.0004 & 0.0223 & 0.0032 & 2.9628 & 1.1065 \\
\hline & & 2 & 0.0099 & 0.0078 & 0.0276 & 0.6218 & 0.4937 & 2.1478 \\
\hline & & 3 & 0.0009 & -0.0008 & 0.0258 & 0.0264 & 2.2267 & 0.7199 \\
\hline \multirow{3}{*}{4} & \multirow{3}{*}{ QUICE } & 1 & 0.0102 & 0.0077 & 0.0578 & 0.6392 & 0.4691 & 2.0137 \\
\hline & & 2 & 0.0012 & -0.0014 & 0.1111 & 0.2341 & 1.1918 & -0.6762 \\
\hline & & 3 & 0.0100 & 0.0075 & 0.0373 & 0.6106 & -0.5096 & -2.0003 \\
\hline \multirow{3}{*}{5} & \multirow{3}{*}{ SHEZ } & 1 & 0.0158 & 0.0128 & 0.0307 & 0.0407 & 2.0546 & -2.3002 \\
\hline & & 2 & 0.0051 & 0.0022 & 0.0359 & 0.1147 & -1.5812 & 1.3218 \\
\hline & & 3 & 0.0000 & -0.0021 & 0.0310 & 0.0025 & 3.0339 & 0.0932 \\
\hline \multicolumn{9}{|c|}{ Insurance } \\
\hline \multirow{3}{*}{1} & \multirow{3}{*}{ AICL } & 1 & 0.0002 & -0.0012 & 0.0294 & 0.0135 & 2.4754 & -0.3994 \\
\hline & & 2 & 0.0080 & 0.0054 & 0.0389 & 0.4846 & -0.6997 & -1.7652 \\
\hline & & 3 & 0.0070 & 0.0060 & 0.0302 & 0.3515 & -0.9322 & -2.6235 \\
\hline \multirow{3}{*}{2} & & 1 & 0.0319 & 0.0294 & 0.0285 & 0.7203 & 0.3584 & 3.5961 \\
\hline & ATIL & 2 & 0.0036 & 0.0011 & 0.0276 & 0.3574 & 0.9214 & -1.1928 \\
\hline & & 3 & 0.0021 & -0.0004 & 0.0207 & 0.0844 & 1.7299 & -0.9149 \\
\hline & & 1 & 0.0000 & -0.0026 & 0.0354 & 0.0645 & 1.8538 & -0.0697 \\
\hline 3 & EFUG & 2 & 0.0031 & 0.0005 & 0.0478 & 0.3737 & -0.8907 & -1.0981 \\
\hline & & 3 & 0.0040 & 0.0015 & 0.0198 & 0.8240 & 0.2225 & -1.2636 \\
\hline & & 1 & 0.0082 & 0.0029 & 0.0342 & 0.9534 & -0.0586 & 1.2497 \\
\hline 4 & IGIIL & 2 & 0.0082 & 0.0029 & 0.0342 & 0.9534 & -0.0586 & 1.2497 \\
\hline & & 3 & 0.0000 & -0.0026 & 0.0272 & 0.0280 & 2.2058 & 0.0091 \\
\hline
\end{tabular}




\begin{tabular}{|c|c|c|c|c|c|c|c|c|}
\hline \multirow{3}{*}{5} & \multirow{3}{*}{ UVIC } & 1 & 0.0192 & 0.0166 & 0.0376 & 0.2464 & 1.1610 & -2.7142 \\
\hline & & 2 & 0.0013 & -0.0014 & 0.0936 & 0.8012 & -0.2519 & -0.6889 \\
\hline & & 3 & 0.0000 & -0.0025 & 0.0997 & 0.2314 & 1.1986 & 0.0690 \\
\hline \multicolumn{9}{|c|}{ Leather } \\
\hline \multirow{3}{*}{1} & \multirow{3}{*}{ BATA } & 1 & 0.0008 & -0.0017 & 0.0284 & 0.0009 & 3.3358 & -0.5639 \\
\hline & & 2 & 0.0011 & -0.0013 & 0.0323 & 0.4375 & 0.7771 & 0.6877 \\
\hline & & 3 & 0.0032 & 0.0015 & 0.0279 & 0.0273 & 2.2130 & -1.3843 \\
\hline \multirow{3}{*}{2} & \multirow{3}{*}{ LEUL } & 1 & 0.0002 & -0.0022 & 0.0616 & 0.4524 & 0.7522 & -0.2760 \\
\hline & & 2 & 0.0001 & -0.0050 & 0.2134 & 0.2926 & 1.0553 & 0.1537 \\
\hline & & 3 & 0.0028 & -0.0003 & 0.1398 & 0.0732 & 1.7975 & 0.9552 \\
\hline \multirow{3}{*}{3} & \multirow{3}{*}{ PAKL } & 1 & 0.0007 & -0.0096 & 0.0350 & 0.2102 & 1.2613 & 0.2652 \\
\hline & & 2 & 0.0042 & -0.0061 & 0.2284 & 0.5950 & 0.5333 & 0.6406 \\
\hline & & 3 & 0.0118 & 0.0016 & 0.1901 & 0.5101 & 0.6611 & -1.0772 \\
\hline \multirow{3}{*}{4} & \multirow{3}{*}{ PSMC } & 1 & 0.0005 & -0.0020 & 0.0246 & 0.6946 & 0.3929 & 0.4632 \\
\hline & & 2 & 0.0257 & 0.0232 & 0.0220 & 0.9849 & -0.0189 & 3.2249 \\
\hline & & 3 & 0.0031 & 0.0005 & 0.0193 & 0.1825 & 1.3355 & -1.0999 \\
\hline \multirow{3}{*}{5} & \multirow{3}{*}{ SRVI } & 1 & 0.0536 & 0.0439 & 0.0372 & 0.0400 & -2.0818 & -2.3443 \\
\hline & & 2 & 0.0277 & 0.0176 & 0.0297 & 0.9255 & 0.0937 & 1.6615 \\
\hline & & 3 & 0.0000 & -0.0103 & 0.0281 & 0.0046 & 2.9012 & -0.0489 \\
\hline \multicolumn{9}{|c|}{ Pharma } \\
\hline \multirow{3}{*}{1} & \multirow{3}{*}{ ABOT } & 1 & 0.0401 & 0.0302 & 0.0193 & 0.1162 & 1.5849 & 2.0121 \\
\hline & & 2 & 0.2368 & 0.2290 & 0.0134 & 0.6691 & 0.4288 & 5.4865 \\
\hline & & 3 & 0.0036 & -0.0067 & 0.0178 & 0.9759 & -0.0303 & -0.5935 \\
\hline \multirow{3}{*}{2} & \multirow{3}{*}{ FEROZ } & 1 & 0.0071 & -0.0031 & 0.0298 & 0.9584 & -0.0523 & 0.8353 \\
\hline & & 2 & 0.0007 & -0.0096 & 0.0270 & 0.7023 & -0.3833 & 0.2686 \\
\hline & & 3 & 0.0017 & -0.0086 & 0.0312 & 0.3039 & 1.0336 & 0.4098 \\
\hline \multirow{3}{*}{3} & \multirow{3}{*}{ GLAXO } & 1 & 0.0022 & -0.0081 & 0.0272 & 0.6524 & 0.4519 & -0.4622 \\
\hline & & 2 & 0.1545 & 0.1457 & 0.0154 & 0.9237 & -0.0960 & 4.2095 \\
\hline & & 3 & 0.0740 & 0.0644 & 0.0283 & 0.9780 & 0.0276 & -2.7832 \\
\hline \multirow{3}{*}{4} & \multirow{3}{*}{ HINON } & 1 & 0.1062 & 0.0970 & 0.0192 & 0.5120 & 0.6581 & 3.3953 \\
\hline & & 2 & 0.0008 & -0.0095 & 0.0157 & 0.1915 & 1.3152 & -0.2851 \\
\hline & & 3 & 0.0068 & -0.0034 & 0.0393 & 0.7473 & 0.3231 & 0.8165 \\
\hline \multirow{3}{*}{5} & \multirow{3}{*}{ SEARL } & 1 & 0.0114 & 0.0012 & 0.0312 & 0.2791 & 1.0883 & 1.0584 \\
\hline & & 2 & 0.0514 & 0.0416 & 0.0121 & 0.9902 & 0.0123 & 2.2922 \\
\hline & & 3 & 0.0412 & 0.0313 & 0.0351 & 0.3916 & 0.8606 & -2.0415 \\
\hline
\end{tabular}


